\title{
Modeling and Evaluation of Political \\ Processes: A New Quantitative Approach
}

\author{
Christian Henning and Johannes Hedtrich
}

\section{Introduction}

A paradox of low political performance exists in many countries (i.e., suboptimal policies persist despite the existence of specific policy instruments that could generate more desirable outcomes). For example, many developing countries that continue to depend largely on agriculture, particularly countries in Sub-Saharan Africa, underinvest in this sector. Especially in areas of public investment that have high returns in terms of growth and poverty reduction, such as agricultural research and extension, public investments remain below the optimal level (Fan and Rao 2003). Accordingly, in addition to an understanding of socioeconomic responses to new policies, avoiding suboptimal agricultural policy choices requires an understanding of the underlying political processes. An improved understanding of the policy process, including the relevant political institutions and their link with the overall political economy, is essential to determining how the participation of stakeholder groups and the use of credible scientific evidence can be promoted in the design and implementation of efficient, pro-poor agricultural strategies. Filling this gap can help identify practical solutions and tools for reducing political performance gaps and facilitate the implementation of improved policies for reducing poverty and promoting growth.

However, policy processes are complex and dynamic by nature; these processes involve multiple actors (i.e., individuals and organizations) and are defined by national political, social, cultural and institutional realities (e.g., constitutional rules), bureaucratic structures and capacities, and the informal participation of stakeholder organizations. Few studies have explicitly mapped these processes to

\footnotetext{
C. Henning $(\bowtie) \cdot J$. Hedtrich

Department of Agricultural Economics, University of Kiel, Kiel, Germany

e-mail: chenning@ae.uni-kiel.de

C. Henning et al. (eds.), Development Policies and Policy Processes in Africa, 
explain the poor past performance of policy reforms and investment strategies, particularly in the agricultural sector. Most of these studies have offered narratives based on historical accounts, emphasizing the strong role of powerful personalities, vested interests, corruption, and external pressures in influencing policy outcomes (Clay and Schaffer 1984; Juma and Clark 1995; Keeley and Scoones 2003; Young 2005). However, theoretical approaches that analyze determinants of policy processes and their impact on poor political performance also exist. One field of the political economy literature holds that biased incentives are the main source of low political performance. Biased political incentives result from asymmetric lobbying activities (Grossman 1994) or biased voter behavior (Bardhan Mookherjee 2002). Further, Persson and Tabellini (2000) emphasize the role of formal constitutional rules as determinants of politician incentives for choosing inefficient policies.

In addition to biased incentives, the lack of adequate political knowledge has also been considered as an explanation for the poor political performance of countries. For example, Beilhartz and Gersbach (2004), Bischoff and Siemers (2011) and Caplan (2007) emphasize the role of biased voter beliefs about policy impacts as a main determinant of inefficient policy choices. Voter beliefs are defined as agents' simplified mental models to approximate the complex true relation between policy instruments and induced policy outcomes. The work of Caplan is highly recognized in the public choice literature, as he collects an impressive amount of evidence for persistently biased voter beliefs. Based on his empirical findings, Caplan draws the rather pessimistic conclusion that democratic mechanisms of preference aggregation naturally lead to the choice of inefficient policies. However, beyond voters, politicians and lobbyists may also fail to fully understand the complex relation between policy instruments and desired policy outcomes. Hence, the lack of political knowledge (i.e., biased policy beliefs) is another important cause of policy failure.

In response to persisting policy failure in many developing countries, participatory and evidence-based political processes are increasingly promoted as an omnipotent tool/mechanism for guaranteeing unbiased political incentives for political agents and allowing the full use of all available political knowledge at both the academic and practical levels. However, designing such ideal-typical policy processes is challenging in political practice. An applicable model framework must first be developed to not only enable a political diagnosis (i.e., the identification of existing incentives and knowledge gaps) but also allow the development of a political therapy (i.e., the derivation of adequate strategies for reducing the identified political performance gaps). The latter criterion requires quantitative modeling of political decisionmaking and policy learning processes, including the endogenous formation of legislator's political preferences and policy beliefs. In a dynamic context, explaining the persistence of a lack of political knowledge requires a further explanation of the reasons for which policy learning fails.

In this context, we suggest an evolutionary Computable General Political Economy Equilibrium Model (eCGPE) as a quantitative approach to modeling and evaluating policy processes. This chapter is focused on the derivation of the eCGPE approach, and the chapters that follow use the implementation of the 
Comprehensive Africa Agriculture Development Programme (CAADP) reform in Malawi to demonstrate how the eCGPE approach can be applied empirically. This chapter is structured as follows: we describe the main structure of an eCGPE approach, then derive the individual modules of the eCGPE in detail, and conclude by providing an outlook on future research.

\section{The Evolutionary Computable General Political Economy Equilibrium Model: An Overview}

\subsection{General Structure and Characterization of an eCGPE}

The eCGPE (Henning and Struve 2008) basically follows the logic of a political economy equilibrium, as proposed by Binswanger and Deininger (1997). This framework makes it possible to examine the economic, political and institutional factors that shape agricultural policy processes. Moreover, the framework allows for the simulation of future policy developments under various economic, political and institutional scenarios.

The CGPE model includes the following modules:

I. A legislative decisionmaking module describing how policy preferences are aggregated to form a final policy choice $\gamma$.

II. An economic module describing the transformation of policies $\gamma$ into outcomes $z$.

III. An interest mediation module describing the transformation of society's welfare $V(z)$ into political support $\mathrm{W}(\mathrm{V}(\mathrm{z}))$ via electoral competition and lobbying.

IV. A belief formation module describing how political agents and voters update their political beliefs via communication.

A non-evolutionary (i.e., static) version of a CGPE model is illustrated in Fig. 1. The evolutionary CGPE approach is a recursive dynamic model that combines the static CGPE (i.e., modules I-IV) with a dynamic political belief updating and adaptive policy learning model. Thus, the evolutionary CGPE approach includes a fifth module:

V. A policy learning module describing how political agents and voters update their political beliefs based on observational learning across time periods.

Figure 2 presents the eCGPE model. The derivation of an eCGPE includes five stages: (1) Economic modeling of policy programs, (2) Modeling of voter behavior and lobbying activities and the derivation of political support functions, (3) Derivation of agents' policy preferences based on political beliefs, (4) Modeling of legislative bargaining determined by agents' policy preferences and constitutional rules, (5) Modeling of belief updating based on observed policy outcomes and 


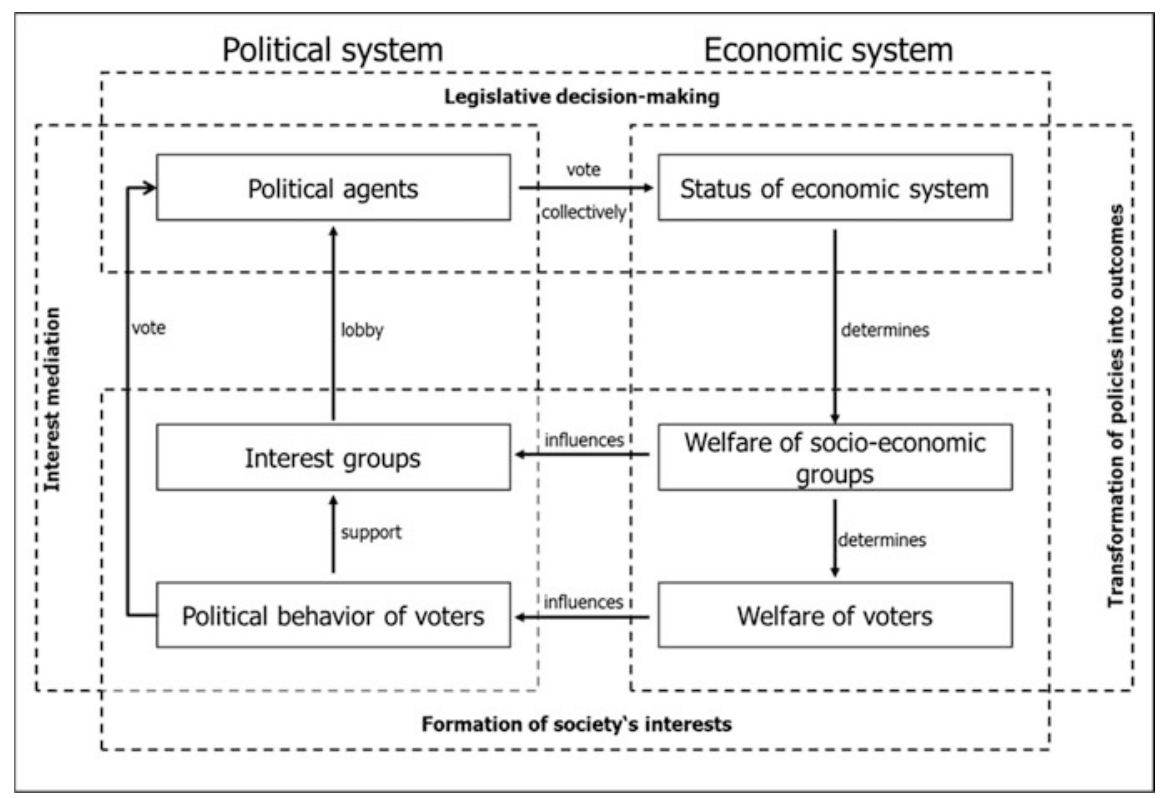

Fig. 1 Computable general political economy equilibrium. Source: Henning (2000)

political communication in networks. The sections that follow will provide the theoretical background required for deriving an eCGPE. However, we will first explain how the tool can be used for policy process evaluation and design.

\subsection{What Is the Purpose and Advantage of a Quantitative Policy Analysis Tool?}

Based on the empirically specified eCGPE model, policy processes can be analyzed, i.e. a political diagnosis identifying political performance gaps can be undertaken. Based on this diagnosis, alternative therapeutic strategies can be simulated.

Specifically, political diagnosis based on a calibrated eCGPE model includes the following steps:

I. Identification of the political performance gap:

- Calculation of the political equilibrium path of sequential eCGPE solutions $\gamma^{* *}$, where $\gamma^{* *}$ denotes the vector of policy instruments selected over a given simulated time period.

- Calculation of an optimal policy $\gamma^{\text {opt }}$ derived from the maximization of the social welfare function $W(z)$ subject to a "best-estimate" political technology. 


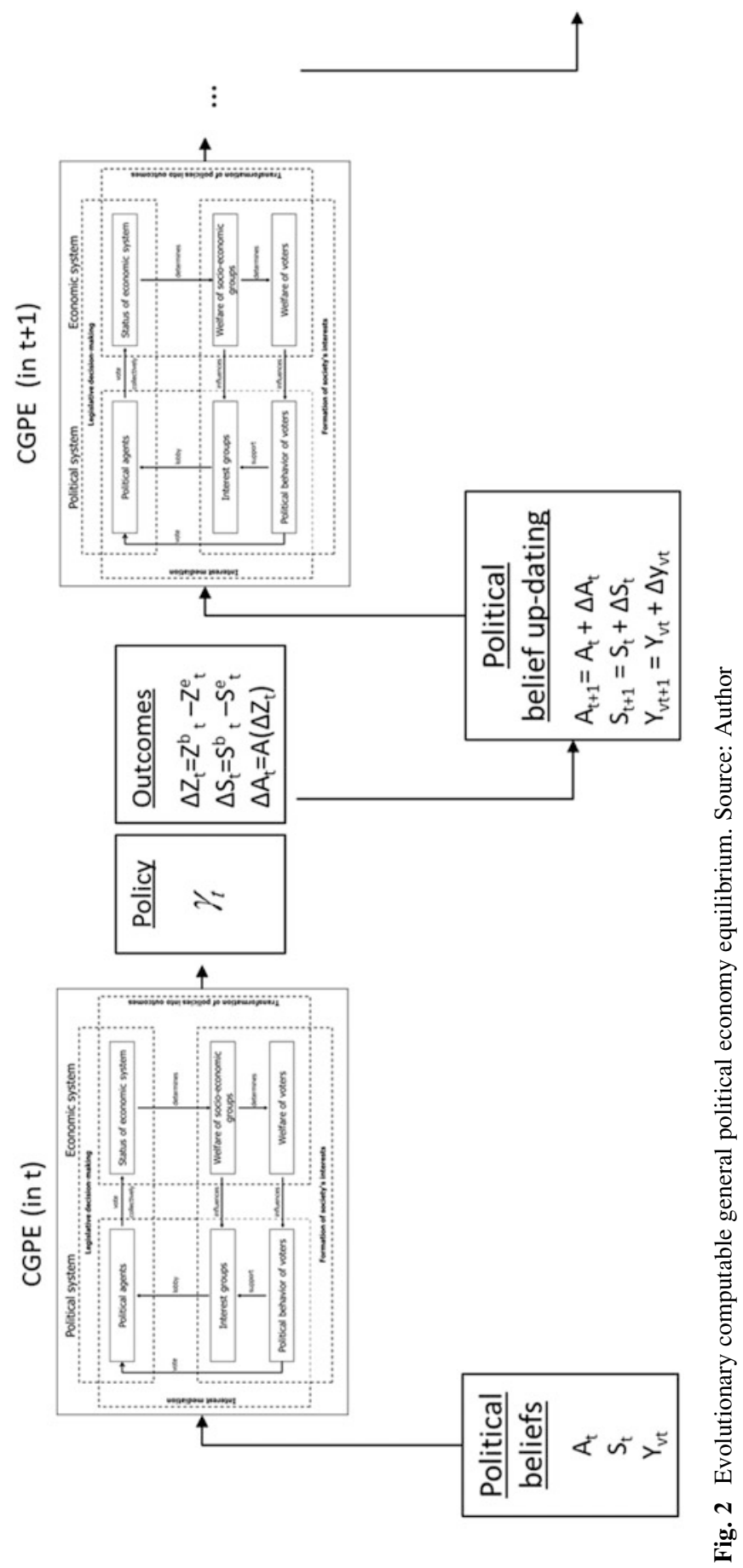


- Calculation of the total performance gap, which is measured as the difference: $\mathrm{W}\left(\gamma^{o p t *}\right)-W\left(\gamma^{* *}\right)$.

II. Identification of the source of the political performance gap:

- Calculation of the knowledge gap as the difference: $W\left(\gamma^{\text {opt }}\right)-W\left(\gamma_{1}^{*}\right)$, where $\gamma_{1}{ }^{*}$ is the policy outcome resulting from the eCGPE simulation runs, assuming all politicians know the "best-estimate" political technology.

- Calculation of incentive gaps as the difference: $W\left(\gamma^{o p t}\right)-W\left(\gamma_{2}^{*}\right)$, where $\gamma_{2}{ }^{*}$ is the policy outcome resulting from the eCGPE simulation runs, assuming all politicians have unbiased support functions that correspond to the social welfare functions.

III. Identification of the main determinants of performance gaps:

- Impact of formal legislative rules and informal lobbying networks

- Simulating policy outcomes and the corresponding political performance under various legislative rules.

- Simulating policy outcomes and the corresponding political performance under various lobbying network structures.

- Impact of policy beliefs of politicians and stakeholders

- Simulating policy outcomes and the corresponding political performance under various political belief formation mechanisms (i.e., changed political communication networks).

- Impact of policy beliefs of voters

- Simulating policy outcomes and the corresponding political performance under various mass political belief formation mechanisms (i.e., changing political communication network structures of different voter groups).

- Impact of innovative policy evaluation and monitoring systems

- Simulating policy learning and implied political performance, assuming the implementation of an effective Monitoring \& Evaluation system.

\section{Theoretical Background of the eCGPE}

\subsection{Module I: Legislative Decisionmaking}

A policy decision is the result of legislative bargaining among a set of legislators $g \in N^{g}$ with heterogeneous policy preferences $U^{g}(\gamma)$. 
Technically, the political decisionmaking model corresponds to the mapping of legislators' policy preferences, $U^{g}$, and constitutional rules for legislative decisionmaking, $\varphi$, into the final policy decision, $\gamma^{*}$ :

$$
\gamma^{*}=\Gamma\left(U^{g}(\gamma), \varphi\right),
$$

where the properties of the function $\Gamma$ correspond to a specific political decisionmaking model. A number of different models have been proposed [see for example the literature review of Binswanger and Deininger (1997)]. In particular, two models have become work horse models in political economy: the legislative bargaining model of Baron and Ferejohn (1989) and the interest group model of Grossman (1994). While the latter model has been frequently applied in empirical studies of agricultural protection (Anderson 2010; Rausser et al. 2011), the former model has become a work horse model in theoretical studies of comparative political economy. However, one advantage of the Baron/Ferejohn model (BF model) is that political decisionmaking is explicitly modeled as a collective decision of many legislators, where constitutional legislative decisionmaking rules are explicit determinants of final political decisions. In contrast, the Grossman/ Helpman model (GH model) focuses on the government or a state agency as a common agent controlling policy choices. Accordingly, this model neglects fundamental collective choice problems that are inherent in real political decisionmaking. The advantage of the $\mathrm{GH}$ model compared to the $\mathrm{BF}$ model is that it can be applied empirically; in contrast, the BF model is a complicated gametheoretical model that cannot be easily applied to real legislative systems.

To combine the advantages of both of these approaches, we suggest a cooperative legislative bargaining model, which can be derived from a modified non-cooperative legislative bargaining model of the Baron-Ferejohn type (Henning 2009). In the following, we briefly describe the main components of the legislative bargaining model; for a more detailed description of the model, we refer the interested reader to our previous work (Henning 2009; Pappi and Henning 1998). Finally, the integration of the GH model into the modified legislative bargaining model is described below in the section that describes Module III.

\subsubsection{The Mean Voter Rule}

Each agent has spatial preferences, where $\widehat{\gamma}_{g}$ denotes agent g's ideal policy position (i.e., the policy he or she wants to be implemented). However, based on constitutional rules, individual legislators need the support of a winning coalition to make their ideal policy positions the final policy choice. Hence, legislative bargaining corresponds to a competition that involves the formation of winning coalitions among political agents. Following the seminal approach of Baron and Ferejohn (1989), we assume that legislative bargaining is a sequential procedure, as described in Fig. 3. 


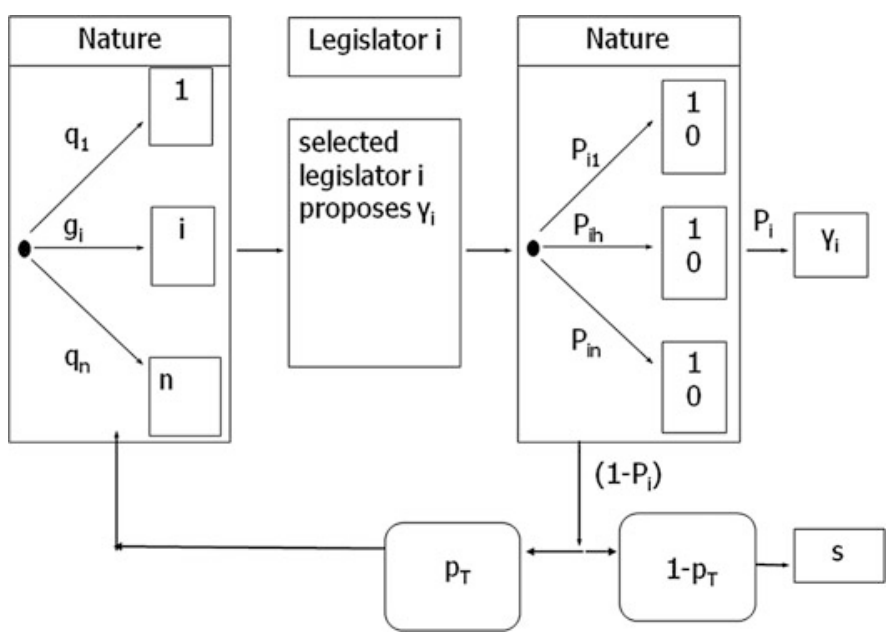

Fig. 3 Game-tree of the modified non-cooperative legislative bargaining game of Baron/ Ferejohn. Source: Henning (2000)

Thus, in each bargaining round, a legislator is randomly selected to formulate a policy proposal. This proposal is submitted to the complete legislature for a majority vote. If the proposal wins a majority of votes, it becomes the new policy; if the proposal fails to win a majority of the votes, the legislative bargaining procedure continues (i.e., a new legislator is randomly selected to formulate a proposal, and the process starts over). However, in contrast to the original BF model, we make two different assumptions. First, we assume that voting on a submitted policy proposal is probabilistic and not deterministic, as assumed by Baron and Ferejohn. In the general approach, the voting probabilities of individual legislators for or against a policy proposal are derived from a probabilistic utility function. To demonstrate the main implications of this assumption, we assume for simplicity in this paper that each legislator $\mathrm{h}$ votes for any policy proposal $\gamma_{g}$ with a fixed probability $P_{g h}=0.5$. Second, following Henning (2000), we assume that the time to draw a legislative decision is typically limited. This assumption implies that the legislature will not consider proposals regarding a specific decision infinitely. Thus, ex post the number of proposals that have been made is always limited, while the number of proposals that will be considered is ex ante not known by individual legislators. Therefore, it is assumed that after each round, there exists a fixed probability $\mathrm{p}_{\mathrm{T}}$ that legislative bargaining continues (i.e., another round will occur). Thus, after each round, the legislative decision procedure stops with a probability $\left(1-p_{T}\right)$ and the status quo policy sustains.

As we previously described in more detail (Henning 2000), the outcome of the modified BF model corresponds to a lottery of the ideal points of individual legislators and the status quo, where the ex ante probability that the ideal point of an individual legislator $g$ will be the outcome of the non-cooperative bargaining is determined by the constitutional rules, and the probability that the legislative 
bargaining procedure continues, $p_{T}$. Let $Q_{g}$ denote the ex ante probability that agent $\mathrm{g}$ succeeds in forming a winning coalition for her policy proposal, while $Q_{s}$ denotes the probability that the outcome of the legislative bargaining is the status quo "s". Under these specific assumptions, the outcome of non-cooperative legislative bargaining corresponds to a lottery over agents' ideal positions and the status quo, where $Q_{g}$ and $Q_{s}$ equal the probability that agent g's ideal policy and the status quo s are selected as the final policy choice, respectively. Assuming that politicians are risk-averse, non-cooperative legislative bargaining is rather inefficient. Hence, agents have an incentive to agree ex ante on cooperative policy formulation mechanisms that guarantee each political agent a higher pay-off.

In particular, it is straightforward to demonstrate that assuming risk-averse legislators, the following mean voter decision rule is a cooperative decisionmaking procedure that ex ante guarantees each individual legislator a higher expected utility than the expected utility derived from the lottery outcome of the non-cooperative legislative bargaining game (see Henning 2000):

$$
\begin{aligned}
E U_{g} & =\sum_{h} Q_{h} U_{g}\left(\gamma_{h}\right)+Q_{s} U_{g}(s) \leq U_{g}\left(\gamma^{M}\right) \quad \text { with }: \quad \gamma^{M} \\
& =\sum_{h} Q_{h} \gamma_{h}+Q_{s} s .
\end{aligned}
$$

Although the mean voter decision rule is ex ante Pareto-dominant compared to non-cooperative legislative bargaining, the mean voter decisionmaking rule does not generally lead to a Pareto-optimal outcome. In particular, from the viewpoint of a legislative majority, the mean voter decision might still be improved. As can be seen from our simple example below, this assertion follows from two facts. First, even if it is assumed that the legislature continues bargaining with a high probability (i.e., pT is significantly larger than 0.5 ), the ex ante probability that the outcome of legislative bargaining will be the status quo is still not negligible. Thus, the mean voter position implies that the new policy is still relatively close to the status quo, where the status quo bias does not necessarily correspond to legislatures preferences but results from the fact that the legislature is busy and has only limited time for bargaining on a specific decision. Second, even if the probability $Q_{s}$ is very low, the mean voter might still be rather inefficient due to the fact that the relative preference intensities for different policy dimensions of different legislators have not been sufficiently taken into account. This scenario is illustrated in Fig. 4, where the mean voter position remains quite distant from the Pareto frontier. Accordingly, Henning (2000) discussed two alternative mechanisms by which legislators can improve the mean voter outcome. As demonstrated in Fig. 4, changing the status quo policy can be considered a two-step procedure, where legislators agree on the direction in which the status quo policy will be shifted in the first step and agree on the distance the status quo policy is shifted towards the agreed direction in the second step. In this context, we suggest the following cooperative policy formulation mechanisms. In a first step, legislators 


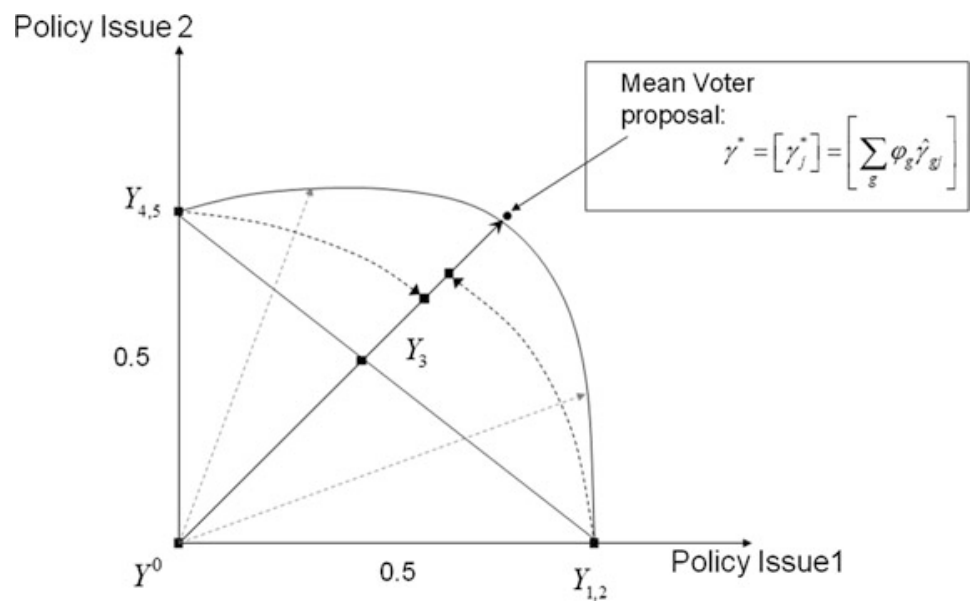

Fig. 4 Utility frontier of a modified non-cooperative legislative bargaining game of the Baron/ Ferejohn type. Source: Author

agree on the direction in which the status quo policy will be shifted. In particular, at the first stage, legislative bargaining results in the following mean voter decision rule:

$$
\Delta \gamma^{*}=\sum_{g} \varphi_{g} \widehat{\gamma}_{g}-\gamma_{0}
$$

$\Delta \gamma^{*}$ denotes the collectively selected direction, where $\sum_{g} \varphi_{g} \widehat{\gamma}_{g}$ is the mean voter position that corresponds to a compromise of legislators' ideal positions. $\varphi_{g}$ corresponds to the relative probability $\frac{Q_{g}}{\sum_{h} Q_{h}}$ that the proposal of a legislator will be the outcome of the non-cooperative legislative bargaining procedure. Hence, $\varphi_{g}$ is determined by formal constitutional rules $\varphi$ and $\varphi_{g}$ can be interpreted as the relative political power of a legislator. Technically, under our simplified assumptions, $\varphi_{g}$ equals the ratio of the number of winning coalitions in which an agent $\mathrm{g}$ is a member and the sum of these numbers for all relevant political agents. Please note that under this assumption, the political power $\varphi_{g}$ is quite similar to the classical normalized Coleman-Banzhaf voting power index (Henning et al. 2006). Given the direction $\Delta \gamma^{*}$, legislators decide on the distance $\lambda_{\gamma}$ at the second stage via voting. As long as legislators' policy preferences, $U^{g}(\gamma)$, are quasi-concave, it follows that legislators have single-peaked preferences regarding the distance $\lambda_{\gamma}$. Accordingly, at the second stage, a unique voting equilibrium outcome results. ${ }^{1}$

\footnotetext{
${ }^{1}$ The proof of single-peakedness is straightforward (Shepsle 1979). Further, please note that even if alternative and more complex voting mechanisms than simple majority voting are assumed, a unique equilibrium outcome results as long as legislators have single-peaked preferences.
} 


\subsubsection{How the Mean Voter Rule Works: An Illustrative Example}

To demonstrate how this model works, we use a simple example comprised of five legislators $\mathrm{g}=1, \ldots, 5$. The legislature must make a two dimensional policy choice, where $\mathrm{j}=1,2$ denote the index of the two policy dimensions (e.g., the policy dimension 1 corresponds to a policy program promoting technical progress in the agricultural sector, while policy dimension 2 corresponds to a policy program promoting technical progress in the non-agricultural sector). Each legislator has a spatial utility function, where $U_{g}(\gamma)=-\sum_{j=1}^{2} \theta_{g j}\left(\gamma-\widehat{\gamma}_{g}\right)^{2}$.

Following the non-cooperative legislative bargaining model of Baron and Ferejohn, legislators are randomly selected, where $\mathrm{q}_{\mathrm{g}}=0.2$ is the probability that a legislator $\mathrm{g}$ is selected to formulate a policy proposal. Legislators vote on a suggested policy proposal with a simple majority, where legislators have different voting weights, $w_{g}$. Hence, a proposal is accepted if the sum of the voting weights of the legislators voting in favor of the proposal exceeds 0.5. For simplicity, we assume that legislators always vote in favor of their own proposal with probability 1 and that legislators vote with a probability of 0.5 for any other policy proposal ${ }^{2}$. Based on these assumptions, the probability that the proposal suggested by a legislator $\mathrm{g}$ will be accepted by a legislative majority depends on the number of winning coalitions of which the proposing legislator is a member. In detail, let $w c$ denote the index of a winning coalition and WC denote the set of all winning coalitions (i.e., all subsets of legislators for which the following holds: $\left.\sum_{g \in w c} w_{g}>0.5\right)$. The number of winning coalitions, $n c_{g}$, of which a legislator $\mathrm{g}$ is a member depends on her voting weight. The voting weights assumed for legislators in our simple example are presented in Table 1. Thus, the number of winning coalitions of which an individual legislator is a member can be calculated as presented in Table 1. Further, given our assumptions, the probability that a specific winning coalition is formed uniquely equals 0.54 for all winning coalitions. Accordingly, the conditional probability that the proposal of a legislator g who was selected to formulate a proposal becomes the final policy outcome can be represented as: $P_{g}=\sum_{i \in w c} 0.5^{4}=n c_{g} 0.5^{4}$. Please note that under these specific assumptions, legislators will always propose their ideal policy when selected to formulate a proposal.

Furthermore, given the structure of the modified legislative bargaining game, the ex ante probability $Q_{s}$ that the status quo will be the policy outcome is (for further details, see Henning 2000):

\footnotetext{
${ }^{2}$ Please note that in the original approach suggested by Henning (2000), the legislators' probability of voting for or against a proposal are endogenously derived from a probabilistic utility function. To simplify the analysis in this paper, we assume that legislators vote for any proposal with a fixed probability of 0.5 .
} 
Table 1 Variables in the simple voting game example

\begin{tabular}{l|l|l|l|l|l|l|l|l}
\hline & $\begin{array}{l}\text { Recognition } \\
\text { probability }\end{array}$ & $\begin{array}{l}\text { Probability } \\
\text { of voting for } \\
\text { proposal }\end{array}$ & $\begin{array}{l}\text { Voting } \\
\text { weights }\end{array}$ & $\begin{array}{l}\text { Number of } \\
\text { winning } \\
\text { coalitions }\end{array}$ & $\mathrm{P}_{\mathrm{T}}$ & $\mathrm{P}_{\mathrm{g}}$ & $\mathrm{Q}_{\mathrm{g}}$ & $\begin{array}{l}\text { Power } \\
(\varphi)\end{array}$ \\
\hline 1 & 0.2 & 0.5 & 0.36 & 12 & & 0.750 & 0.206 & 0.245 \\
\hline 2 & 0.2 & 0.5 & 0.35 & 11 & & 0.688 & 0.189 & 0.224 \\
\hline 3 & 0.2 & 0.5 & 0.15 & 10 & & 0.625 & 0.172 & 0.204 \\
\hline 4 & 0.2 & 0.5 & 0.08 & 8 & & 0.500 & 0.137 & 0.163 \\
\hline 5 & 0.2 & 0.5 & 0.06 & 8 & & 0.500 & 0.137 & 0.163 \\
\hline $\begin{array}{l}\text { Status- } \\
\text { quo }\end{array}$ & 0 & 0 & 0 & 0 & & & 0.160 & 0.000 \\
\hline Total & 1 & & 1 & 49 & 0.70 & & 1.000 & 1 \\
\hline
\end{tabular}

Source: Author

$$
Q_{s}=\frac{\left(1-p_{T}\right)\left(1-\frac{1}{5} \sum_{h} P_{h}\right)}{1-p_{T}+p_{T} \frac{1}{5} \sum_{h} P_{h}}
$$

Moreover, the probability that the ideal point of legislator $g$ will be the final outcome of the legislative bargaining procedure can be calculated $\mathrm{as}^{3}$ :

$$
Q_{g}=\frac{1}{5} P_{g} \sum_{t=0}^{\infty}\left(\sum_{h \in N_{g}} \frac{1}{5}\left(1-P_{h}\right) P_{T}\right)^{t}=\frac{P_{g}}{\sum_{h \in N_{g}} P_{h}}\left(1-Q_{s}\right)=\left(1-Q_{s}\right) \frac{n c_{g}}{\sum_{h} n c_{h}}
$$

As demonstrated in Table 1, given the assumed voting weights, we can calculate the equilibrium outcome of the modified BF model. Further, we can calculate the mean voter position (i.e., the direction in which the status quo will be shifted). Finally, given the direction $\Delta \gamma^{*}=(0.127,0.070)$, we can also calculate the legislators' preferred distance $\lambda_{g}{ }^{4}$ :

${ }^{3}$ Please note that the following holds: $1-Q_{s}=\frac{1 / 5 \sum_{h} P_{h}}{1-p_{T}+p_{T} \frac{1}{5} \sum_{h} P_{h}}$.

${ }^{4}$ Please note that Eq. (6) directly follows from the maximization of agent's g spatial policy preferences, assuming each policy proposal must lie on the line connecting the status quo to the mean voter position. 
Table 2 Outcomes of the simple voting game example

\begin{tabular}{|c|c|c|c|c|c|c|c|}
\hline \multirow[b]{2}{*}{ Player } & \multicolumn{2}{|c|}{ Policy position } & \multicolumn{2}{|c|}{ Policy interest } & \multirow{2}{*}{\begin{tabular}{|l} 
Direction \\
$\lambda$ \\
\end{tabular}} & \multicolumn{2}{|c|}{ Final Outcome } \\
\hline & Issue 1 & Issue 2 & Issue 1 & Issue 2 & & Issue 1 & Issue 2 \\
\hline 1 & 1 & 0 & 0.7 & 0.3 & 1.678 & & \\
\hline 2 & 1 & 0 & 0.65 & 0.35 & 1.598 & & \\
\hline 3 & 0.5 & 0.5 & 0.5 & 0.5 & 1.166 & & \\
\hline 4 & 0 & 1 & 0.2 & 0.8 & 1.922 & & \\
\hline 5 & 0 & 1 & 0.3 & 0.7 & 1.576 & & \\
\hline Status quo & 0 & 0 & & & & & \\
\hline Total & 0.480 & 0.360 & & & 1.598 & 0.768 & 0.576 \\
\hline
\end{tabular}

Source: Author

$$
\lambda_{g}=\frac{\sum_{j} \theta_{g j}\left(\widehat{\gamma}_{g j}-\gamma_{j}^{0}\right) \Delta \gamma_{j}^{*}}{\sum_{j} \theta_{g j}\left[\Delta \gamma_{j}^{*}\right]^{2}} .
$$

The voting outcome at the second stage corresponds to the preferred distance of the median legislator, where the median legislator is the legislator for whom it holds that the sum of the voting weights of legislators preferring a lower distance and the sum of the voting weights of legislators preferring a higher distance are both lower than 0.5 . In our example, legislator 1 is the median legislator (i.e., the outcome in the second step will be to shift the policy by a distance $\left.\lambda^{*}=1.598\right)$. Accordingly, the final policy outcome of our bargaining equilibrium will be (see also Table 2 and Fig. 4):

$$
\gamma^{*}=\gamma^{0}+\lambda^{*} \Delta \gamma^{*}=0+1.598^{*}(0.480,0.360=(0.768,0.567)
$$

Please note that our example demonstrates the inefficiency of non-cooperative bargaining (e.g., in Fig. 4, the mean voter position remains rather distant from the Pareto frontier). In general, policy outcomes are stochastic under non-cooperative bargaining (i.e., risk-averse legislators prefer the mean voter rule as a deterministic cooperative decisionmaking procedure). Further, legislators are less able to coordinate their actions under the one-step mean voter rule than under the two-step procedure (e.g., legislators collectively prefer a shift of the status quo beyond the mean voter position (i.e., $\lambda_{g}$ is larger than 1 for all legislators) (see Table 2).

\subsubsection{Endogenous Derivation of Legislators' Policy Preferences}

To calculate legislative bargaining outcomes, the policy preferences of legislators must be known. Legislators' spatial policy preferences $U^{g}(\gamma)$ are derived from political support maximization: 


$$
U^{g}(\gamma)=\operatorname{Max}\left\{W^{g}(z) \mid T(z, \gamma) \equiv 0\right\},
$$

where $W^{g}(z)$ denotes the political support function and $T(z, \gamma)$ denotes the political technology transforming policy $\gamma$ into political outcomes z. $\widehat{\gamma}_{g}$ denotes legislator g's ideal point [i.e., the policy that maximizes Eq. (8)]. The political technology $\mathrm{T}$ is determined by the economic system and is modeled in Module II, while the political support function $\mathrm{W}$ is determined by voter behavior and lobbying activities, as described below in the section that describes Module III.

In most existing legislative decisionmaking models, legislators' preferences are exogenously given. However, to derive legislators' spatial policy preferences endogenously from the political support maximization in Eq. (8), we apply a second order Taylor approximation developed at the legislator's ideal position:

$$
U_{g}(\gamma)=\sum_{j} \sum_{k} \theta_{g j k}\left(\gamma_{j}-\widehat{\gamma}_{g j}\right)\left(\gamma_{k}-\widehat{\gamma}_{g k}\right) .
$$

$\theta_{g j k}$ are the weighting factors of the interaction term of the deviation of the policies $\mathrm{j}$ and $\mathrm{k}$, which are technically derived from the second order derivations of the maximization problem in Eq. (8). Please note that this approach for deriving endogenous policy preferences follows Henning and Struve (2008) and that similar approaches exist in the literature (de Gorter and Swinnen 1998; Fafchamps et al. 1993). However, the latter approaches fail to derive complete endogenous policy preferences for individual political agents and integrate them directly into a legislative decisionmaking model.

A simple approach for deriving endogenous policy preferences results from a linear approximation of the political technology:

$$
T(z, \gamma): z=z^{0}\left(1+w_{z}\right) \quad \Leftrightarrow \quad w_{z}=A \Delta \gamma+a_{0}
$$

$a_{0}$ denotes the vector of the growth rates of policy concerns $\mathrm{z}$, which are realized assuming the status quo policy sustains, while $A \Delta \gamma=A\left(\gamma-\gamma_{0}\right)$ denotes the vector of growth rates of policy concerns $\mathrm{z}$, which are induced by a change from the status quo policy $\gamma_{0}$ to the policy $\gamma$.

Please note that the linear approximation of the political technology (i.e., the matrix A) changes with changing economic framework conditions. Hence, the impact of different economic framework conditions (e.g., changed world market prices) on endogenous policy preferences can be analyzed within this approach (Henning and Struve 2008).

Overall, legislators' policy preferences depend not only on political technology but also on the properties of the political support function (i.e., voter behavior and lobbying activities), which we will discuss in further detail in Module III below. Finally, as we will discuss in more detail in Module IV below, we assume that legislators have very limited knowledge regarding the true political technology. 
Accordingly, legislators form political beliefs to approximate the unknown political technology.

\subsection{Module II: Transformation of Policy Choices into Policy Outcomes}

\subsubsection{Computable General Equilibrium Model (CGE)}

The economic module corresponds to any economic model that characterizes the general structure and economic responses of the national economy that is under consideration to policy changes. By default, we use the standard recursive dynamic CGE model suggested by International Food Policy Research Institute (IFPRI) (Löfgren 2001). As the model is fully described elsewhere, we will not provide a detailed description of the model here. Interested readers are recommended to read the relevant literature (Löfgren 2001).

\subsubsection{Policy Impact Function}

The core of a standard CGE application corresponds to the simulation of shocks, where shocks are defined as exogenous shifts in policies or economic framework conditions. To simulate policies within a CGE approach, the policies must be implemented into the CGE model. Some policies (e.g., direct and indirect taxes or tariffs) are already directly implemented in the standard CGE model. However, other policies, (e.g., structural adjustment policies, policy programs aiming to increase technical progress in economic sectors or policies aiming to improve market access for enterprises [i.e., reducing transaction costs]), must be translated into CGE parameters. Dynamic CGE models explicitly incorporate parameters representing sector-specific technical progress, as well as sector-specific transaction costs, subsidy payments and tariffs (see Löfgren 2001). While modeling the impact of technical progress in different economic sectors on the growth of the average per-capita income, on income distribution and on poverty is straightforward, the translation of different policy instruments into sector-specific technical progress or transaction costs is by no means straightforward within a CGE approach.

In this context, we suggest the implementation of a policy impact function. This function is defined as a transformation of policy instruments into relevant CGE parameters that correspond to sector-specific technical progress or transaction costs. Specifically, let $\beta$ denote the vector of relevant CGE-parameters corresponding to sector-specific technical progress or transaction costs, while $\gamma$ denotes the vector of relevant policy instruments. We then define a policy impact function as the mapping of policy instruments into relevant CGE parameters: $\beta=\operatorname{PIF}(\gamma)$. 
To demonstrate how policy impact functions can be applied within the framework of our CGPE approach, we focus below on technical progress, which is a major determinant of future poverty reduction and economic growth (Diao et al. 2007; Fan and Rosegrant 2008). Fan and Rosegrant (2008) emphasize that many African countries spend far too little on the promotion of technical progress in the agricultural sector compared to the non-agricultural sector. The overall effectiveness of total spending depends on the allocation of funds across different policy programs. For example, within the Comprehensive Agricultural Development Plan, four different pillars are specified, including a wide range of policy programs (for details, see Chapter "The Formation of Elite Communication Networks in Malawi: A Bayesian Econometric Approach" below). Moreover, total welfare is also determined by the provision of public goods, such as health, education and other social services. Therefore, at the country level, the overall budget allocation must include the distribution of total financial resources to policy programs promoting economic growth in the agricultural and non-agricultural sectors, as well as the allocation of financial resources for the provision of public goods. For example, Badiane et al. (2011) clearly demonstrate that budget allocation among policies promoting future economic growth and the provision of public goods has a significant impact on present and future welfare developments.

Thus, to identify optimal government budget allocations that promote maximal economic growth within our CGPE framework, we suggest the following two-stage policy impact function approach. Total government expenditure $B_{g o v}$ results as the sum of total spending across policy programs:

$$
B_{t o t}=\sum_{p \in P o l} \gamma_{p}
$$

The effective impact of total government spending on the technical progress $\mathrm{tp}_{s}$ that is realized in a specific economic sector s depends on the allocation of spending across policy programs. All other things being equal, technical progress in the agricultural sector is higher with higher spending on agricultural policy programs. However, total agricultural spending is subdivided across different agricultural policy programs. For example, within CAADP, four key focus areas for agricultural improvement and investment are formulated: (1) Sustainable Land and Water Management, (2) Market Access, (3) Food Supply and Hunger, and (4) Agricultural Research. To account for the effects of different policy programs $p \in P$ on the technological progress realized in a specific sector $\mathrm{s}$, the following two-stage policy impact functions $P I F^{s}(\gamma)$ are defined for each sector s:

$$
P I F^{s}(\gamma)=\bar{t} p_{s} \frac{\exp \left(a_{s} B_{s}^{e f f}-b_{s}\right)}{1+\exp \left(a_{s} B_{s}^{e f f}-b_{s}\right)},
$$




$$
B_{s}^{e f f}=\omega_{s}\left[\sum_{p} \mu_{s p}\left(\gamma_{p}\right)^{-\rho^{I F}}\right]^{-1 / \rho^{I F} .}
$$

According to the assumed two-stage function, it follows that for each sector, an optimal budget allocation $s h_{s p}$ can be defined by:

$$
\frac{s h_{s p}}{s h_{s q}}=\left(\frac{\mu_{s p}}{\mu_{s q}}\right)^{1 /(1+\rho)}, \sum_{p} s h_{s p}=1 .
$$

Assuming that $\omega_{s}$ is accordingly normalized implies that for an optimal budget allocation, the effective budget equals total budget $B_{s}^{\text {eff }}(\gamma)=B_{t o t}(\gamma)=\sum_{p} \gamma_{p}$. In contrast, for any nonoptimal budget allocation, the effective budget is lower than the total budget. At the lower stage, budget allocation is transformed into effective budget allocation following a CES-function specification. At the upper stage, an effective budget is translated into technical progress according to a logistic function (i.e., the maximal technical progress that can be achieved via governmental policy is determined by $\bar{t} p_{s}$, where the marginal impact of additional effective budget spending is diminishing and approximates zero for a sufficiently large effective budget). Please note that optimal budget allocation across the total set of policy programs varies across different sectors. This scenario implies that the same budget allocation across policy programs in different sectors translates into different effective budgets that induce different rates of technical progress $t p$.

The suggested policy impact function basically follows the work of Fan and Zhang (2004). However, in contrast to that original approach, our two-stage approach is more general and implies a nonlinear relationship between governmental spending and induced sectoral growth. Moreover, this approach explicitly considers the composition of budget spending for different policy programs. Further, a similar approach was also suggested by Bourguignon et al. (2008a, b) in their MAM model (Maquette for MDG Simulations), which models the impact of different policy instruments on Millennium Development Goals (MDGs).

\subsection{Module III: Interest Mediation Module}

Module III captures the two main channels for the mediation of society's interests in a democracy: electoral competition and lobbying. We apply a modified BaronGrossman Helpman model to simultaneously capture both voter behavior and lobbying activities. 


\subsubsection{Modeling Voter Behavior}

Voter behavior corresponds to voters' electoral response to governmental policies. According to the probabilistic voter theory, electoral competition implies that legislator g's political support functions, $W^{g}(z)$, correspond to the weighted social welfare functions of the voter groups represented in his constituency (Persson and Tabellini 2000):

$$
W^{g}(z)=\sum_{v} w_{g v} V^{v}(z)
$$

In Eq. (15), $v$ denotes the index of voter groups and $\mathrm{w}_{\mathrm{gv}}$ dentoes the political weight of an individual voter $\mathrm{v}$ for the political agent $\mathrm{g}$. In general, the probability that a voter of group $v$ votes for a candidate or party in an election depends on the expected utility $V_{v}(z)$ that the voter perceives assuming the candidate will be elected.

In a perfect political world, electoral competition would be based on the policy platforms, $\gamma_{A}$ and $\gamma_{B}$, suggested by candidates A and B, respectively. Voters would evaluate candidates based on their policy platform (i.e., voters transform policy platforms into their individual welfare according to the political technology, $T(Z, \gamma)$, and vote for the candidate whose policy platform implies the highest utility).

However, because in the real world, the transformation of policies into welfare is rather complex, the calculation of expected utility is also rather complex from the viewpoint of individual voters. Hence, voters apply simple heuristics to estimate their expected utility.

In general, voters apply different types of policy and non-policy indicators to estimate the expected future utility, assuming a candidate is elected. Non-policyoriented indicators correspond to the concept of valence (Groseclose 2001; Schofield 2004; Stokes 1963), which is based on specific characteristics $z_{I}$, such as appearance, charisma, occupation or ethnicity. Based on these characteristics, voters perceive a specific competence or popularity of candidates and parties. Moreover, following Grossman and Helpman (1996), we also assume that voters are at least partially swayed by the relative campaign spending of different parties. These effects may reflect the influence of election advertisements or other efforts made to mobilize support (e.g., election rallies, door-to-door visits by campaign workers, etc.). Assuming, for simplicity, a two-party (i.e., two-candidate) setup below implies that voters perceived the following utility based on non-policy indicators and the relative campaign spending of the candidates:

$$
V_{I}^{v}\left(z_{I}, C^{g}\right)=V_{0}^{v}\left(z_{I}\right)+\chi\left(C^{g}-C^{g^{\prime}}\right) .
$$

$V_{I}^{v}\left(z_{I}, C^{g}\right)$ is the ideological component of voters' perceived utility, where $C^{g}$ denotes the campaign spending of party $g$ and $C^{g}$ denotes the campaign spending of party g'. 
In addition to non-policy indicators, voters also base their votes on policy indicators. A set of policy indicators corresponds to the concept of retrospective voting (Paldam and Nannestad 2000) (i.e., voters use observable welfare indicators (e.g., income growth or other well-being indicators) that were realized in the past period when an incumbent was in office to update their evaluation of the competence/popularity of the incumbent). Please note that retrospective voting can be interpreted as reinforcement learning. Let $V_{R}^{v}\left(z_{r}\right)$ denote the retrospective component of voters' perceived utility.

To the extent that valence indicators and campaign spending are not correlated with political competence, non-policy voting implies a bias. Moreover, non-policy voting implies no incentives for legislators to prefer efficient policies. In contrast, retrospective voting implies such incentives (i.e., based on retrospective voting, support-maximizing legislators prefer policies that lead to a maximal observable social welfare). However, retrospective voting becomes problematic when technological relations between policies and social welfare become more complex (e.g., if time lags occur between the adoption of a policy and its impact on measurable welfare indicators). Public investment in education is a good example, as these investments will increase long-term welfare growth, but positive welfare impacts will not be realized for a decade or more. In the short run, these investments might even reduce welfare. Thus, assuming long-term welfare growth with short-term costs, retrospective voting undermines the incentives for support-seeking legislators to implement long-term growth policy strategies. Analogously, the implementation of environmental policies that promote sustainable welfare growth in the long run might be undermined by retrospective voting.

Therefore, a third component that determines voter choices corresponds to voters' perceived utility that is derived directly from the observed policy platforms of candidates. However, voters have very limited knowledge regarding the true political technology. Accordingly, voters form beliefs (i.e., they apply simple mental models that approximate the true political technology).

In particular, we assume that voters reduce the multi-dimensional policy space $\gamma$ to a lower dimensional macro-policy space $z_{p}$. For example, pro-poor growth policy or agricultural-driven growth can be interpreted as macro-policy strategies. Specific policies $\gamma$ (e.g., agricultural sector polices, as defined within CAADP) can be mapped into these strategies. At a second stage, voters transform macro-policies into utility, again applying simple linear mapping as a mental model. Under these assumptions, the policy-oriented component of voters' utility can be represented by a spatial utility function $V_{p}^{v}\left(z_{p}\right)$, which is defined in the macro-policy space.

Overall, voter behavior is determined by the importance of the non-policy, retrospective and policy-oriented components of voters' perceptions of their utility, which are derived from the election of different candidates or parties. In general, it is possible to estimate the importance of the different utility components by econometrically applying a probabilistic voter approach (for example, see Schofield 2007) Based on the empirically specified probabilistic voter model, we derive the political support function of political agents as follows: 


$$
\begin{aligned}
W_{g}(z, C) & =V_{g}(z)+\chi\left(C^{g}-C^{g^{\prime}}\right) \\
& =\sum_{v} \alpha_{g v}\left(V_{0}^{v}\left(z_{I}\right)+V_{R}^{v}\left(z_{R}\right)+V_{P}^{v}\left(z_{P}\right)\right)+\chi\left(C^{g}-C^{g^{\prime}}\right) .
\end{aligned}
$$

\subsubsection{Lobbying Activities}

Following the Grossman-Helpman model (1996), lobbying groups $\mathbf{J}=1, \ldots, \mathrm{n}_{\mathrm{J}}$ contribute to the campaign finances of the relevant parties; these contributions are conditioned on party platforms $C_{J}^{g}\left(\gamma^{g}\right)$. The lobbying game has two stages. In the first stage, the lobby offers nonnegative conditional contributions $C_{J}^{g}\left(\gamma^{g}\right)$. In a second stage, each party selects a policy to maximize its vote share. In this stage, a party g selects a policy $\gamma^{g}$ to maximize:

$$
W^{g}(z)=V^{g}(z)+\sum_{J} \chi_{J}^{g} C_{J}^{g}(\gamma) \text { s.t. } T(z, \gamma)=0 .
$$

Further, it can be demonstrated that when the lobbying game is in equilibrium, each lobby group will select a support schedule for each party that induces a policy choice to maximize the net expected utility of a contributing member. Because the legislative bargaining among legislators is a lottery of legislators' ideal points, the net expected utility of changing party g's platform can be expressed as: $\varphi_{g} V_{J}\left(\gamma^{g}\right)-\frac{1}{n_{J}} C_{J}^{g}\left(\gamma^{g}\right)$, where $\mathrm{n}_{\mathrm{J}}$ denotes the number of members of interest group $\mathrm{J}$. Therefore, in this case, the policy choice $\widehat{\gamma}$ of a legislator $\mathrm{g}$ is selected to maximize:

$$
V^{g}(z)+\varphi_{g} \sum_{J} \chi_{J}^{g} \frac{n_{J}}{n} V_{J}\left(\gamma^{g}\right) \text { s.t.T }(z, \gamma)=0 .
$$

Furthermore, in a one-shot game, as originally assumed by Grossman and Helpman, interest groups have an incentive to renege on their contribution offers once legislators have announced their platforms. Similarly, legislators have no incentives to pursue their announced positions once the campaign contributions have been paid. Hence, Grossman and Helpman motivate the keeping of premises in a repeated game, where agents would be punished for failure to fulfill their promises. However, even in a repeated game, the potential of agents to commit to their premises is limited and the commitment power depends on the frequency of interaction and the possibility of exchanging information with other agents regarding the opportunistic behavior of an individual agent (Dixit 2003). Accordingly, as long as both participation in the lobby game and reliable information relations with other agents differ across lobby groups and legislators, it follows that not every lobby group can engage in a lobby game with every legislator. Empirically, the 
access structures among lobbying groups and legislators can be measured via corresponding political network data (Pappi and Henning 1998, 1999; Henning 2009). Formally different access structures are reflected in the relative weights, $\chi_{J}^{g}$.

\subsection{Module IV: Belief Formation Module}

To cope with complexity, laymen, politicians and representatives of interest groups apply naive mental models to understand how policies translate into policy outcomes (i.e., agents form political beliefs). Some scholars (Blendon et al. 1997; Caplan 2002; Rhoads 1985; Walstad 1996) compared the policy beliefs of laymen to the corresponding expert beliefs of trained economists. Based on comprehensive statistical analyses, Caplan concluded that laymen beliefs systematically differ from experts beliefs. In particular, Caplan concluded that these differences result from judgmental anomalies of the general public. In contrast, on average, economic experts hold unbiased and true beliefs. Interestingly, Caplan and other scholars (Akerlof 1989; Caplan 2001; Sachs and Williamson 1994) further concluded that political failure is more likely to be a byproduct of the electorate's systematically biased beliefs about economics than a product of special interest politics.

The mechanism by which actors form their beliefs is of interest. The modeling of belief formation and belief updating has recently become an increasingly acknowledged field of research in economics and social science (see Acemoglu and Ozdaglar 2010; Golub and Jackson 2009; Jackson 2008). Following the relevant literature, we distinguish two types of belief formation: observational and communication learning. Dynamic policy learning corresponds to observational learning, where, as will be shown in detail below, from the viewpoint of an individual actor, it often makes sense to combine observational learning and communication learning. As will be shown in more detail in the following subsections, in our theory, a central determinant of policy learning corresponds to communication structures among agents, which are encapsulated in communication networks. The question of which specific network structure implies effective policy learning and thereby guarantees more efficient policy decisions is central to our theory. In this paper, we focus our analysis on the belief updating of governmental and nongovernmental organizations, leaving the analysis of voter belief formation and updating for future work. ${ }^{5}$

\footnotetext{
${ }^{5}$ The main reason for not explicitly taking voter beliefs into account at this point follows from the difficulty of collecting reliable data concerning voter communication networks and voter behavior that allow for the estimation of the underlying voter beliefs and the process of voters' belief formation. However, the analysis of political elite networks is a well-established field in the empirical policy network literature (Knoke et al. 1996; Henning 2009; Henning and Krampe 2011; Pappi and Henning 1998; Pappi and Henning 1999).
} 


\subsubsection{Communication Learning}

Collective belief formation via communication learning corresponds to the mapping of agents' initial individual beliefs $\tilde{A}^{0}$ into final beliefs, as follows: $\tilde{A}=\Upsilon\left(\tilde{A}^{0}\right)$, where $\Upsilon$ corresponds to a specific communication mechanism. Following recent studies (Acemoglu and Ozdaglar 2010; Golub and Jackson 2009), we assume that agents form their beliefs via communication in local networks. To consider communication structures, we define a binary network $M^{1}$ over a set of agents $N$, where $M_{i j}^{1}=1$ indicates that agent $i$ and agent $j$ have an established communication tie. Accordingly, we define the subset $M_{i}=\left\{j \in N, M_{i j}^{1}=1\right\}$ as the neighborhood of agent $i$ and $M=\left[m_{i j}\right]$ as a communication network, where $m_{i j}>0$ indicates that actor i pays attention to actor $\mathrm{j}$. $\mathrm{M}$ is a stochastic matrix; for each actor, the sum of the total weights equals 1 :

$$
\sum_{j \in M_{i}} m_{i j}=1 \quad m_{i j}=\frac{M_{i j}^{1}}{\sum_{j^{\prime} \in M_{i}} M_{i j^{\prime}}^{1}} .
$$

Within one period, a political communication process occurs, where agents repeatedly update their political beliefs by taking weighted averages of their neighbors' beliefs, with $m_{i j}$ being the weight or trust that actor i places on the current belief of agent $\mathrm{j}$ when forming his or her belief for the next period (see also Golub and Jackson 2009). If we let $r=1, \ldots, R$ denote the communication round, then it follows that:

$$
\tilde{A}_{i}^{r+1}=m_{i i} \tilde{A}_{i}^{0}+\sum_{j \neq i} m_{i j} \tilde{A}_{j}^{r}
$$

Rewriting Eq. (21) results in the following:

$$
\begin{aligned}
& \tilde{A}_{i}^{r+1}=m_{i i} \tilde{A}_{i}^{0}+\left(1-m_{i i}\right) \cdot \sum_{j} \bar{m}_{i j} \tilde{A}_{j}^{r} \\
& \text { with }: \bar{m}_{i j}=\frac{m_{i j}}{\left(1-m_{i i}\right)},
\end{aligned}
$$

where $\tilde{A}_{i}^{r}$ is the political belief of agent $i$ that results after $\mathrm{r}$ communication rounds, and $A_{i}^{0}$ denotes agent $i$ 's initial beliefs prior to communication. The parameter $m_{i i}$ represents the weight actor i puts on her own initial belief. As $M$ is row normalized to one, $\left(1-m_{i i}\right)$ is the aggregated weight for all neighbors (i.e., the influence or communication field of other agents). Writing Eq. (22) in matrix notation results in the following, after further rearrangements: 


$$
\tilde{A}=\left[I-\left(1-m_{\text {diag }}\right) \bar{M}\right]^{-1} \cdot m_{\text {diag }} \cdot \tilde{A}^{0},
$$

with $\widehat{M}=\left[I-\left(1-m_{\text {diag }}\right) \bar{M}\right]^{-1} m_{\text {diag }}$ being the network multiplier, which is similar to the Hubbell index (Hubbell 1965). Please note that the belief updating in Eq. (23) corresponds to the Friedkin model (Friedkin and Johnsen 1990) and includes the DeGroot model analyzed by Jackson 2008 as a special case. In particular, for any row stochastic matrix $\widehat{M}$, belief formation converges to a well-defined limit $\tilde{A}$. Accordingly, the limit beliefs of each agent that are reached via communication correspond to the weighted average of the initial beliefs of all agents prior to communication $\tilde{A}^{0}$, where the weight of agent $j$ 's initial opinion $\tilde{A}_{j}^{0}$ determining agent $i$ 's belief after communication $\tilde{A}_{i}$ equals the element $\widehat{m}_{i j}$ of the multiplier matrix $\widehat{M}$. The multiplier $\widehat{m}_{i j}$ defines the field strength of agent $j$ 's initial belief operating on agent $i$ 's final belief.

Note that the multiplier includes all communication loops among actors (i.e., all direct and all indirect effects of $j$ 's initial belief on the belief of agent $i$ that result from communication). Overall, the efficiency of communication learning is determined by the extent that communication network structures imply that the relative weights of agents' initial opinions correspond with the agents' relative political knowledge. For the deGroot model, this issue has been analyzed by Golub and Jackson (2009) (see also Jackson 2008). Golub and Jackson (2009) demonstrated that c.p, a random communication process (i.e., agents update their beliefs randomly based on the communicated beliefs of all other actors) implies unbiased beliefs, assuming the number of agents approximates infinity. In contrast, assuming communication is structured in such a way that the weight of an individual agent will not approximate zero when the number of agents approximates infinity implies biased beliefs. However, Golub and Jackson failed to analyze the impact of communication network structures on communication learning in finite societies. Thus, in the following section, we will analyze this interesting relation by applying a simple example.

\section{Communication Networks and Policy Learning: A Simple Example}

To demonstrate how communication network structures impact the efficiency of policy learning, consider the following simple example of a political elite system comprised of the simple legislative system introduced above and five stakeholder groups. The legislators are labeled L1 to L5, and the stakeholder groups are labeled IG1 to IG5.

For simplicity, we assume that legislators must decide on the expenditure for a specific policy program $\mathrm{X}$. Let $\mathrm{X}$ correspond to financing for agricultural extension services. The legislators and stakeholders are concerned about the impact of the 
policy program $\mathrm{X}$ on a political objective $\mathrm{Z}$. Let $\mathrm{Z}$ be the reduction of poverty. Assume that a simple linear technical relation describes the impact of budget allocation to agricultural extension services $X$ on poverty reduction $Z$ : $Z=a X$.

Further, assuming quasi-linear preferences $\mathrm{V}(\mathrm{Z}, \mathrm{B})$ :

$$
V(Z, B)=\left\{Z^{\eta}+\theta(B-X)\right\},
$$

where $\mathrm{B}$ denotes the state budget and $\theta$ is a parameter determining the marginal utility of budget expenditures. The optimal expenditure that results from the maximization of $\mathrm{V}(\mathrm{Z}, \mathrm{B})$ can be expressed as:

$$
\widehat{X}=\theta^{\frac{1}{\eta-1}} \eta^{\frac{1}{1-\eta}} a^{\frac{\eta}{1-\eta}}
$$

All other things being equal, the more efficiently the program $\mathrm{X}$ impacts poverty reduction (i.e., the larger $a$ becomes), the larger is the amount of financial resources that legislators want to invest into this program. For simplicity, we assume specific parameter constellations $(\eta=0.5$ and $\theta=0.0625)$, such that it follows that: $\widehat{X}=a$.

As described above, the fundamental uncertainty of the technological impact of policy programs on policy targets is a major problem in political decisionmaking. Thus, agents must form beliefs. In particular, we assume that agents observe a signal from which they derive their initial beliefs. The signals are independently but not necessarily identically distributed. As a result, it holds that:

$$
a_{i}=a+\varepsilon_{i} .
$$

$\varepsilon_{i}$ is the bias, which is symmetrically distributed with a mean of zero and a variance $\sigma_{i}^{2}$. Accordingly, the initial belief is a random variable $\widehat{a}_{i}$ that is distributed with mean a and a finite variance $\sigma_{i}^{2}$. Thus, the expected error an agent makes when deriving her policy position form her initial beliefs equals $E\left(\varepsilon_{i}^{2}\right)=\sigma_{i}^{2}$.

Next, we analyze the manner in which belief updating via political communication, as described above, impacts the bias of legislators' beliefs and the subsequent error that results for the preferred policy position, $\widehat{X}$. As described above, following our model of communication learning, the final belief of an individual agent corresponds to a weighted mean of legislators' initial beliefs, where the weight of the position of an agent $\mathrm{j}$ for the final belief of agent $\mathrm{i}$ equals the network multiplier $\widehat{m}_{i j}$. Thus, it holds:

$$
\widehat{a}_{i}^{1}=\sum_{j} \widehat{m}_{i j} \widehat{a}_{j}^{0}=\sum_{j} \widehat{m}_{i j}\left(a+\varepsilon_{j}\right)=a+\sum_{j} \widehat{m}_{i j} \varepsilon_{j} .
$$

Define $\mathrm{E}_{i}=\sum_{j} \widehat{m}_{i j} \varepsilon_{j}$ as the bias of agent i's belief after communicational learning. Then, the error an agent i makes when deriving his policy position from 
his final beliefs corresponds to the weighted sum of the individual errors of all agents:

$$
E\left(\mathrm{E}_{i}\right)^{2}=\sum_{j} \widehat{m}_{i j}{ }^{2} \sigma_{j}^{2}
$$

Hence, optimal weights $\left(m_{i} j^{\text {opt }}\right)$ can be defined by minimizing the error after communication learning:

$$
\frac{m_{i j}^{o p t}}{m_{i k}^{o p t}}=\frac{\sigma_{k}^{2}}{\sigma_{j}^{2}} ; \quad m_{i k}^{o p t}=\frac{\frac{1}{\sigma_{k}^{2}}}{\sum_{j} \frac{1}{\sigma_{j}^{2}}} .
$$

Please also note that if individual biases, $\varepsilon_{i}$, are drawn from an identical distribution with variance $\sigma^{2}$, it directly follows that the optimal weights equal $1 / n$, where " $n$ " is the number of political agents. Accordingly, communication learning reduces the policy bias by an order of $\mathrm{n}$ when compared to an individual updating. Specifically, it holds: $E\left(\mathrm{E}_{i}\right)^{2}=\frac{1}{n} \sigma^{2}$. This process basically corresponds to the wisdom of the crowd effect, which was initially identified by Francis Galton (1907).

More generally, we can conclude from our analyses above that an essential precondition for efficient communication learning in networks is that actors' communication structures guarantee that the relative political knowledge of agents is reflected in their relative network multipliers. As can be seen from eq. (29) the relative political knowledge of actors is measured by the ratio of their corresponding error variances. Hence, it is important to identify a strategy for designing policy network structures that imply efficient policy learning. In particular, we must determine under which conditions a stronger participation of stakeholder organizations in the political communication process implies more efficient learning. To this end, we apply our network model to simulate policy learning under different conditions of political knowledge distribution among legislators and stakeholder groups and under different communication network structures. In detail, we simulated three ideal-typical policy network structures corresponding to (1) top-down communication (i.e., stakeholders update based on the communicated beliefs of politicians, not vice-versa); (2) bottom-up communication (i.e., politicians update based on the communicated beliefs of stakeholders, not viceversa and (3) equal participation of stakeholders (i.e., politicians update based on the beliefs of stakeholders, and stakeholders update based on the beliefs of politicians). The blocked network structure of the three scenarios is presented in Table 3 .

The assumption that politicians put a lower weight on their own beliefs (i.e., politicians are generally more open to influence from other actors compared to interest groups) implies the average network multipliers for the three network constellations that are presented in Table 4.

Finally, we assume that the individual bias is the same for all political actors in the scenario "equal-know" and that the relation of the variance of the individual error terms is 4 times higher for the politician than for the stakeholder organizations 
Table 3 Ideal-typical political communication structures

\begin{tabular}{|c|c|c|c|c|c|c|}
\hline & \multicolumn{6}{|c|}{ Scenarios } \\
\hline & \multicolumn{2}{|c|}{ Top-down } & \multicolumn{2}{|c|}{ Equal } & \multicolumn{2}{|c|}{ Bottom-up } \\
\hline & $L$ & $I G$ & $L$ & $I G$ & $L$ & $I G$ \\
\hline$L$ & 1 & 0 & 1 & 1 & 0 & 1 \\
\hline$I G$ & 1 & 0 & 1 & 1 & 0 & 1 \\
\hline
\end{tabular}

Source: Author

Source: Author

\begin{tabular}{|c|c|c|c|c|c|c|}
\hline & \multicolumn{6}{|c|}{ Scenarios } \\
\hline & \multicolumn{2}{|c|}{ Top-down } & \multicolumn{2}{|c|}{ Equal } & \multicolumn{2}{|c|}{ Bottom-up } \\
\hline & $L$ & $I G$ & $L$ & $I G$ & $L$ & $I G$ \\
\hline$L$ & 1 & 0 & 0.51 & 0.49 & 0.3 & 0.7 \\
\hline$I G$ & 0.4 & 0.6 & 0.11 & 0.89 & 0 & 1 \\
\hline
\end{tabular}

Table 4 Network multiplier derived for ideal-typical political communication structures

in the scenario "IG-expert". We also assume that the average variance across all political actors remains constant. In contrast, we assume in the scenario "polexpert" that the politicians exhibit a fourfold lower error term variance than the stakeholder organizations. We again assume that the average variance across all agents remains constant.

Following our exposition above, we calculated the average expected belief bias of the legislators for all 9 network and knowledge constellations. Further, we calculated the optimal weighting of agents' initial individual beliefs for all knowledge scenarios. Based on these calculations, we computed the average additional bias that will be realized for a given policy network constellation and a specific knowledge scenario compared to the corresponding optimal communication structure. We expressed this additional bias as the percentage of the bias that is realized under conditions of optimal belief updating. Analogously, we calculated the relative efficiency gain obtained via communicational learning for all three network structures in comparison to individual belief formation. In particular, we compared the average error that results from communication learning to the average error that results assuming individual belief formation among politicians.

Figure 5 clearly demonstrates that the efficiency of policy learning depends on the combination of a specific knowledge distribution and communication structure, where a mismatch between these two components implies extreme losses of efficiency. Assuming that interest groups have more political knowledge than politicians, a top-down communication structure implies an average error due to biased beliefs that is $400 \%$ higher than the error that results from an optimal communication structure. However, the corresponding efficiency loss amounts to only $62 \%$ when assuming a balanced communication structure. In contrast, assuming politicians have significantly higher knowledge implies an increase in the policy error of $150 \%$ for a bottom-up communication structure and $51 \%$ for a balanced communication structure (see Fig. 5). 


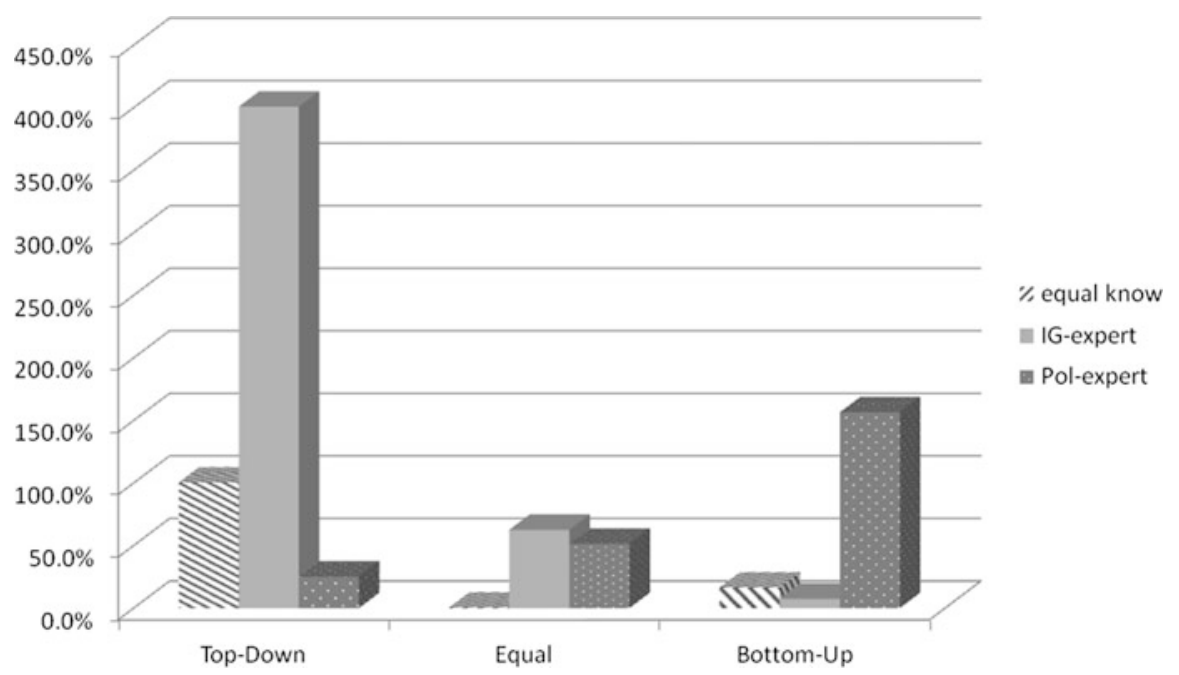

Fig. 5 Efficiency loss resulting from communication policy learning in different knowledge and policy network scenarios. Source: own calculation

Further, a comparison of the policy errors that result from communication learning to the corresponding errors that are implied by individual belief formation emphasizes the efficiency of communication learning. Specifically, communication learning reduces the policy error by over $90 \%$ compared to individual learning for all scenarios.

Overall, this simple simulation study implies that stakeholder participation significantly increases the efficiency of communication learning. The ignorance of stakeholder organizations, as assumed for the top-down scenario, only increases the efficiency of policy learning when the relative political knowledge of stakeholder organizations is much lower than that of politicians.

In contrast, focusing policy learning solely on stakeholder organizations, as implied by the bottom-up communication structure, would only be justified if stakeholders have significantly higher knowledge than politicians.

Finally, it is also interesting to identify the conditions under which evidencebased political processes that focus policy learning on a small subset of political experts (e.g., research institutions) increase the efficiency of policies. To this end, we calculated the optimal relative weight of one policy expert, assuming that this expert's relative political knowledge compared to the average agents in the network increases from 1 (i.e., equal knowledge) to 100 (i.e., the error variance of the average agent is 100 times higher than error variance of the expert). Moreover, we calculated the efficiency gain as a percentage comparing the relative error that results under an optimal communication structure to that of a balanced communication structure. The simulation results are presented in Fig. 6. Figure 6 demonstrates that the efficiency gain that results from a focus on political experts increases in a concave manner with the relative expertise of the expert and is dependent on the 


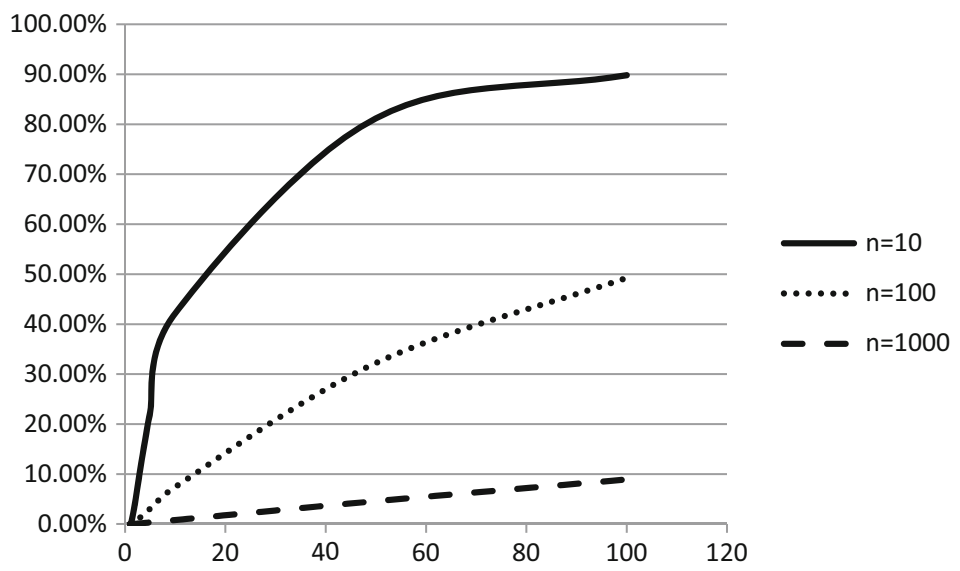

Fig. 6 Efficiency gain resulting from optimal centralization of communication on political experts according to the size of the elite network. Source: Author

size of the total policy elite network. For a small network that includes only ten governmental and nongovernmental organizations, the relative gain amounts to only $10 \%$, assuming that the expert's knowledge is threefold higher. In contrast, the relative gain amounts to nearly 90\%, assuming that the expert's knowledge is 100-fold higher.

These gains are significantly lower for larger networks (e.g., for an elite network with 100 organizations, a maximal efficiency gain of $50 \%$ is realized, but for an elite network comprised of 1000 organizations, the maximal efficiency gain is reduced to only $9 \%$ ).

Accordingly, the optimal centralization of political communication on experts decreases significantly with the size of the elite network. Assuming a network size of 10 implies that the optimal communication structures correspond to a significant centralization of the political communication on political experts, with a Herfindahl index ranging from 0.1 for equal knowledge to 0.89 assuming political knowledge is 100 times higher for the expert. In contrast, the corresponding Herfindahl indices range from 0.01 to 0.25 for a network size of 100 and from 0.001 to only 0.009 for an elite network size of 1000 (see Fig. 7).

\subsection{Observational Policy Learning}

While communication learning is possible within a static CGPE approach, belief updating might also occur dynamically (e.g., across time periods). Dynamic policy learning corresponds to a belief updating process that is based on observed policy outcomes. These outcomes can be realizations of political targets (e.g., in our simple example above, agents observe the development of poverty in their 


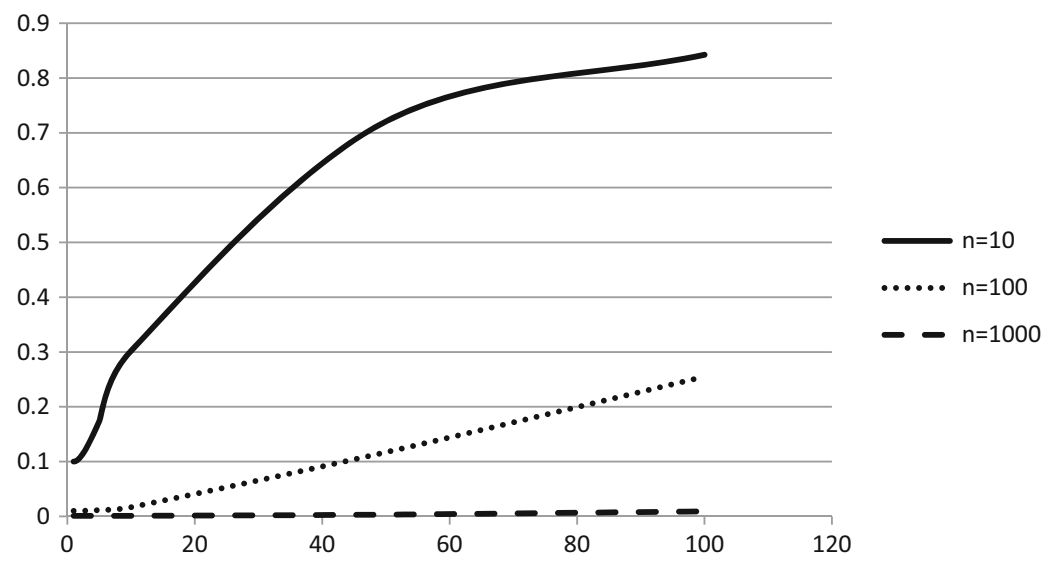

Fig. 7 Optimal centralization of communication on political experts according to the size of the elite network, as measured using the Herfindahl index. Source: Author

constituency after a specific policy X has been implemented). Agents compare the observed policy outcome with the policy outcomes they expected based on their original policy beliefs. Hence, if the observed outcomes differ from the expected outcomes, the agents have an incentive to adapt their beliefs to ensure that expected outcomes match observed outcomes:

$$
\begin{gathered}
Z_{i t}^{E}=\widehat{a}_{i t-1} X_{t-1}, \\
\Delta \widehat{\mathrm{a}}_{i t}=\phi \Delta Z_{t}=\phi\left(Z_{i t}^{O}-Z_{i t}^{E}\right), \\
\widehat{\mathrm{a}}_{i t}=\widehat{\mathrm{a}}_{i t-1}+\Delta \widehat{\mathrm{a}}_{i t} .
\end{gathered}
$$

Thus, agents update their political beliefs proportional to the relative difference between observed $Z^{O}$ and expected $Z^{E}$ policy outcomes, where $\phi$ denotes the speed of adjustment parameter. Hence, we assume a Nerlovian belief updating process. Nerlovian policy learning that is based on individual observation of policy outcomes becomes complex when more than one policy program impacts policy outcomes. In this case, politicians might update based on available scientific policy evaluation studies (e.g., impact evaluation studies for specific policy programs). These studies deliver direct estimates of specific technical parameters, a.

\subsection{Reinforcement Learning}

While observational policy learning based on observed policy outcomes z implies that political agents actually apply a mental model, which may be simple, to estimate how policies translate into outcomes, reinforcement learning does not require a mental model. 
Reinforcement learning implies that agents choose their future behavior based on the perceived gratification received from past behavior (i.e., if this gratification is positive, agents repeat or intensify their past behavior, but agents stop or reduce their past behavior if the perceived gratification is negative). Retrospective voting is a prominent example of reinforcement political learning. In this scenario, a voter's probability of reelecting the government depends on the voter's perceived welfare that was realized while the government was in power. However, in contrast to voters, politicians are interested in reelection. Hence, their observed political support triggers reinforcement learning.

To explain how reinforcement learning works in a policy choice setting, please note that according to the two-stage legislative bargaining procedure described above, politicians perceive multidimensional policy choices in a one-dimensional macro-policy space. The macro-policy space corresponds to the direction in the multidimensional policy space in which agents agree to shift the status quo policy. Given the direction $\Delta \gamma^{*}$, agents decide on the distance $\lambda_{\gamma}$, where legislators have single-peaked preferences for this distance, with $\widehat{\lambda}_{g}$ denoting an agent's ideal distance. Let $\lambda_{t}^{*}$ denote the final policy choice in period that results from majority voting at the second stage of legislative bargaining. Then, legislators observe the political support feedback that results from the implementation of the policy $\gamma_{t}^{*}=\gamma^{0}+\lambda_{t}^{*} \Delta \gamma^{*}$. If the feedback is positive, politicians have an incentive to shift the status quo even further in the same direction $\Delta \gamma^{*}$, but if the support feedback is negative, legislators have an incentive to move the policy back towards the direction of the status quo. Formally, we assume the following reinforcement learning mechanism:

$$
\gamma_{t}=\gamma^{0}+\lambda_{t}^{*} *\left(\Delta \gamma^{*}\right)
$$

Updated policy choices are based on observed changes in political support:

$$
\begin{gathered}
\lambda_{0}=0 ; \quad 0<\lambda_{1}<<1, \\
d \lambda_{t}^{*}=\lambda_{t}^{*}-\lambda_{t-1}^{*}, d \widehat{\lambda}_{t}^{g}=\widehat{\lambda}_{t-1}^{g}-\lambda_{t-1}^{*}, \\
d W_{t}=W_{t}\left(\gamma_{t}\right)-W_{t-1}\left(\gamma_{t-1}\right), \\
\Delta \lambda_{t}=\operatorname{sgn}\left(d W_{t} * d \lambda_{t}\right), \\
\lambda_{t+1}^{g}=\begin{array}{c}
\lambda_{t}^{g}+\phi \Delta \lambda_{t} \lambda_{1}, \quad \text { if } d \lambda_{t}^{*} d \widehat{\lambda}_{t}^{g}<0 \\
\lambda_{t}^{g}, \quad \text { otherwise }
\end{array} .
\end{gathered}
$$

where $\phi$ is again a parameter determining the speed of adjustment. Because political support is a single-peaked function of $\lambda$, reinforcement learning will gradually identify the optimal policy strategy. In more specific terms, without an adequate stop strategy, reinforcement learning will lead to an oscillating process in which policy decisions oscillate between $\left(\lambda^{*}-\phi \lambda_{1}, \lambda^{*}+\phi \lambda_{1}\right)$, where $\lambda^{*}$ is the support-maximizing policy decision. Thus, the finer the adjustment (i.e., the 
lower the step length $\phi \lambda_{1}$ ) the closer reinforcement learning mechanisms mimic optimal policy choices.

\subsection{Combination of Observational and Communication Learning}

Analogously, observations of policy outcomes $z_{t}$ by individual agents are noisy. Thus, if we again assume idiosyncratic measurement errors, which are independent draws from a distribution with a zero mean, the aggregated measurement of policy outcomes is almost correct, but individual measures might be highly biased. Therefore, agents might be willing to combine their individual observational learning with communication learning. To describe the combined learning process, let $\Delta \tilde{\mathrm{a}}_{i t}^{0}$ denote the individual parameter update that results from the observational learning of an agent $i$ in period $t$. Then, combined observational and communication learning implies that the final parameter updates correspond to:

$$
\Delta \tilde{\mathrm{a}}_{i t}^{1}=M \Delta \tilde{a}_{i t}^{0} .
$$

Based on the updated beliefs, a new political decision results from legislative bargaining in period $t+1$.

\section{Summary and Conclusion}

This chapter develops the eCGPE as a theoretical framework and an empirically applicable tool for defining, evaluating and designing efficient participatory and evidence-based policy processes. The eCGPE is a sequential dynamic political economy equilibrium model that incorporates five modules that model legislative decisionmaking, the transformation of policies into socioeconomic outcomes, interest mediation via voting and lobbying, political belief formation and policy learning. In contrast to existing political economy models, which highlight the biased incentives of politicians as a main cause of persisting inefficient policies, the CGPE approach explicitly incorporates the lack of adequate political knowledge as another important source of inefficient policy choices. In particular, the CGPE approach incorporates a model of political belief formation and updating to explain how political agents use a combination of observational and communication learning processes to improve their political knowledge. According to our model, the main determinants of the speed of knowledge are the structures of policy networks that reflect communication patterns between governmental and nongovernmental organizations. Based on empirical policy network data, relevant communication structures can be identified. Combining the identified network structures with the 
relative political knowledge of the involved governmental and nongovernmental organizations allows for an assessment of the impact of stakeholder participation on the efficiency of policy learning. The knowledge of the involved organizations is derived from the specified economic model, specifically from the political impact function. Moreover, within an extended Grossman-Helpman approach, the impact of lobbying activities and voting behavior on politician incentives is modeled. In this model, the asymmetric lobbying activities of vested interest groups are determined by limited access to powerful politicians. The latter can be empirically identified by applying social network analysis. Furthermore, we demonstrate that based on the eCGPE approach, a political diagnosis can be made (i.e., existing incentives and knowledge gaps can be identified). Furthermore, a political therapy (i.e., adequate strategies for reducing existing political performance gaps) can be derived via simulation analyses based on the eCGPE. To empirically apply a CGPE approach, all five modules must be specified, the model parameters must be empirically estimated and the specified modules must be implemented using an adequate programming framework. In the four sections that follow, we will describe how the CGPE approach can be empirically applied using the policy network study on the CAADP reforms in Malawi as an example. In Chapter "A Network Based Approach to Evaluate Participatory Policy Processes: An Application to CAADP in Malawi", the empirical application of the political belief updating module and the legislative decision-making module is described, while Chapter "The Formation of Elite Communication Networks in Malawi: A Bayesian Econometric Approach", describes the econometric estimation of the network datagenerating process of relevant policy networks in Malawi. In Chapter " Voter Behavior and Government Performance in Malawi: An Application of a Probabilistic Voting Model", a probabilistic voter model is estimated using Afrobarometer data from Malawi. Finally, in Chapter "Whither participation? Evaluating participatory policy processes with the CGPE approach: The case of CAADP in Malawi", the complete eCGPE approach is applied to the recent CAADP reform in Malawi to demonstrate how this approach can be applied as a practical tool for analyzing policy processes empirically.

\section{References}

Acemoglu, D., and A.E. Ozdaglar. 2010. Opinion Dynamics and Learning in Social Networks. MIT Department of Economics Working Paper 10-15. Cambridge: Massachusetts Institute of Technology.

Akerlof, G.A. 1989. The Economics of Illusion. Economics and Politics 1: 1-15.

Anderson, K. 2010. The Political Economy of Agricultural Price Distortions. Cambridge: Cambridge University Press.

Badiane, O., S.P. Odjo, and F. Wouterse. 2011. Comparative Analysis of Strategies and Long Term Outlook for Growth and Poverty Reduction among ECOWAS Member Countries. Discussion paper. West and Central Africa Office.

Bardhan, P., and D. Mookherjee. 2002. Relative Capture of Local and Central Governments: An Essay in the Political Economy of Decentralization. Working Paper C99-109. Berkeley: Center of International and Development Economics Research. 
Baron, D., and J. Ferejohn. 1989. Bargaining in Legislatures. American Political Science Review 83: $1181-1206$.

Beilhartz, H.-J., and H. Gersbach. 2004. General Equilibrium Effects and Voting Into a Crisis. CEPR Discussion Paper 4454. London: Centre for Economic Policy Research.

Binswanger, H.P., and K.W. Deininger. 1997. Explaining Agricultural and Agrarian Policies in Developing Countries. Journal of Economic Literature 35: 1958-2005.

Bischoff, I., and L.-H. Siemers. 2011. Biased Beliefs and Retrospective Voting: Why Democracies Choose Mediocre Policies. Public Choice 156: 163-180.

Blendon, R.J., J.M. Benson, M. Brodie, R. Morin, D.E. Altman, D. Gitterman, M. Brossard, and M. James. 1997. Bridging the Gap between the Public's and Economists' Views of the Economy. Journal of Economic Perspectives 11: 105-118.

Bourguignon, F., M. Bussolo, and L.A.P. da Silva, eds. 2008a. The Impact of Macroeconomic Policies on Poverty and Income Distribution. Washington, DC: World Bank.

Bourguignon, F., C. Diaz-Bonilla, and H. Löfgren. 2008b. Aid, Service Delivery, and the Millenium Development Goals in an Economy-Wide Framework. Washington, DC: World Bank.

Caplan, B. 2001. Rational Irrationality and the Microfoundations of Political Failure. Public Choice 107: 311-331.

. 2002. Systematically Biased Beliefs about Economics: Robust Evidence of Judgemental Anomalies from the Survey of Americans and Economists on the Economy. The Economic Journal 112: 433-458.

- 2007. The Myth of the Rational Voter - Why Democracies Choose Bad Politics. Princeton, NJ: Princeton University Press.

Clay, E., and B. Schaffer, eds. 1984. Room for Maneuver: An Exploration of Public Policy in Agriculture and Rural Development. London: Heinemann.

De Gorter, H., and J.F.M. Swinnen. 1998. The Impact of Economic Development on Public Research and Commodity Policies in Agriculture. Review of Development Economics 2: 41-60.

Diao, X., P. Hazel, D. Resnick, and J. Thurlow. 2007. The Role of Agriculture in Development: Implications for Sub-Saharan Africa. IFPRI Discussion Paper 153. Washington, DC: International Food Policy Research Institute.

Dixit, A. 2003. Trade Expansion and Contract Enforcement. Journal of Political Economy 111: 1293-1317.

Fafchamps, M., E. Sadoulet, and A. de Janvry. 1993. Tariff Seeking in a General Equilibrium Framework. Journal of International Trade \& Economic Development 2: 167-189.

Fan, S., and N. Rao. 2003. Public Spending in Developing Countries: Trends, Determination and Impact. EPTD Discussion Paper 99. Washington, DC: International Food Policy Research Institute.

Fan, S., and X. Zhang. 2004. Investment, Reforms and Poverty in Rural China. Economic Development and Cultural Change 52 (2): 395-422.

Fan, S., and M.W. Rosegrant. 2008. Investing in Agriculture to Overcome the World Food Crisis and Reduce Poverty and Hunger. IFPRI Policy Briefs 3. Washington, DC: International Food Policy Research Institute.

Friedkin, N.E., and E.C. Johnsen. 1990. Social Influence and Opinions. Journal of Mathematical Sociology 15: 193-205.

Galton, F. 1907. Vox Populi. Nature 75: 450-451.

Golub, B., and M.O. Jackson. 2009. Naive Learning in Social Networks and the Wisdom of Crowds. American Economic Journal Microeconomics 2 (1): 112-149.

Groseclose, T. 2001. A Model of Candidate Location When One Candidate Has a Valence Advantage. American Journal of Political Science 45: 862-886.

Grossman, J.B. 1994. Evaluating Social Policies: Principles and U.S. Experience. The World Bank research observer 9 (2): 159-180. 
Grossman, G.M., and E. Helpman. 1996. Electoral Competition and Special Interest Politics. Review of Economic Studies 63: 265-286.

Henning, C.H.C.A. 2000. Macht und Tausch in der europäischen Agrarpolitik: Eine positive politische Entscheidungstheorie. Frankfurt/Main: Campus.

2009. Networks of Power in the CAP System of the EU-15 and EU-27. Journal of Public Policy 29: 153-177.

Henning, C.H.C.A., and E. Krampe. 2011. How the European Union Works: Theory and Empirical Evidence from EU Agricultural Policy. Paper presented at the Political Economy of International Organizations (PEIO), Zurich, Switzerland.

Henning, C.H.C.A., C. Struve, B. Brümmer, and L. Seidel, eds. 2006. Macht und Ideologie in der EU-25: Eine Anwendung eines Generalisierten Banzhaf-Index auf die Europäische Agrarpolitik. In Schriften der Gesellschaft für Wirtschafts- und Sozialwissenschaften des Landbaues e.V. Kiel: Agrar- und Ernährungswissenschaftliche Fakultät.

Henning, C.H.C.A., and C. Struve. 2008. The Logic of the European Agricultural Policy: Political Power or Economic Rules? German Journal of Agriculture Economics 57: 179-194.

Hubbell, C.H. 1965. An Input-Output Approach to Clique Identification. Sociometry 28 (4): 377-399.

Jackson, M.O. 2008. Social and Economic Networks. Princeton, NJ: Princeton University Press.

Juma, C., and N. Clark. 1995. Policy Research in Sub-Saharan Africa: An Exploration. Public Administration and Development 15: 121-137.

Keeley, J., and I. Scoones. 2003. Understanding Environmental Policy Processes. In Africa: Cases from Ethiopia, Mali and Zimbabwe. Earthscan: London.

Knoke, D., F.U. Pappi, J. Broadbent, and Y. Tsujinaka. 1996. Comparing Policy Networks. Labor Politics in the U.S., Germany, and Japan. Cambridge: Cambridge University Press.

Löfgren, H. 2001. Less Poverty in Egypt? Explorations of Alternative Pasts with Lessons for the Future. Discussion Paper 72. Washington, DC: International Food Policy Research Institute.

Paldam, M., and P. Nannestad. 2000. What do Voters Know about the Economy? A Study of Danish Data 1990-1993. Electoral Studies 19: 363-391.

Pappi, F.U., and C.H.C.A. Henning. 1998. Policy Networks: More than a Metaphor? Journal of Theoretical Politics 10 (4): 553-575.

1999. The Organization of Influence on EC's Common Agricultural Policy: A Network Approach. European Journal of Political Research 36 (2): 257-281.

Persson, T., and G. Tabellini. 2000. Political Economics-Explaining Economic Policy. Cambridge: MIT Press.

Rausser, G.C., J. Swinnen, and P. Zusman. 2011. Political Power and Economic Policy: Theory, Analysis, and Empirical Applications. Cambridge: Cambridge University Press.

Rhoads, S. 1985. The Economist's View of the World: Government, Markets, and Public Policy. Cambridge: Cambridge University Press.

Sachs, J., and J. Williamson, eds. 1994. Life in the Economic Emergency Room. In The Political Economy of Policy Reforms, 501-524. Washington, DC: Institute for International Economics.

Schofield, N. 2004. Equilibirium in Spatial Valence Models of Politics. Journal of Theoretical Politics 16: 447-481.

Schofield, N.J. 2007. The Mean Voter Theorem: Necessary and Sufficient Conditions for Convergent Equilibrium. Review of Economic Studies 74: 965-998.

Shepsle, K.A. 1979. Institutional Arrangements and Equilibrium in Multidimensional Voting Models. American Journal of Political Science 23 (1): 27-59.

Stokes, D.E. 1963. Spatial Models of Party Competition. American Political Science Review 57: 368-377.

Walstad, W. 1996. Economic Knowledge and the Formation of Economic Beliefs. In Economic Socialization: The Economic Beliefs and Behaviors of Young People, ed. P. Lunt and A. Furnham, 162-182. Cheltenham: Edward Elgar.

Young, J. 2005. Research, Policy and Practice: Why Developing Countries Are Different. Journal of International Development 17: 727-734. 
Christian Henning is professor and chair of agricultural economics, University of Kiel (Germany). He studied economics, agricultural economics, sociology, political science and mathematics. He earned a PhD in economics, in agricultural economics and in political science. His main areas of specialization are applied political economy and applied economic modelling of agricultural policies. To date he has published five books and various articles in refereed journals including PLoS ONE, American Journal of Agricultural Economics, European Review of Agricultural Economics, Journal of Public Policy, Journal of Mathematical Sociology and Journal of Theoretical Politics.

Johannes Hedtrich is a computer scientist and a $\mathrm{PhD}$ student in agricultural economics. $\mathrm{He}$ studied computer science and agricultural economics at the University of Kiel (Germany). His main areas of specialization are computational economics, Bayesian econometrics and social network analysis.

Open Access This chapter is licensed under the terms of the Creative Commons Attribution 4.0 International License (http://creativecommons.org/licenses/by/4.0/), which permits use, sharing, adaptation, distribution and reproduction in any medium or format, as long as you give appropriate credit to the original author(s) and the source, provide a link to the Creative Commons license and indicate if changes were made.

The images or other third party material in this chapter are included in the chapter's Creative Commons license, unless indicated otherwise in a credit line to the material. If material is not included in the chapter's Creative Commons license and your intended use is not permitted by statutory regulation or exceeds the permitted use, you will need to obtain permission directly from the copyright holder.

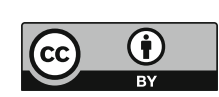

